\title{
Forces at the interface of gradability and quantification*
}

\author{
Elizabeth Coppock \\ Boston University \\ University of Gothenburg
}

\author{
Elizabeth Bogal-Allbritten \\ University of Gothenburg
}

\begin{abstract}
This paper ties together four cross-linguistic generalizations: (i) proportional readings for quantity superlatives are typologically marked; (ii) adverbial superlatives have only relative readings; (iii) quantity superlatives agree in number with the noun on proportional, but not relative readings; (iv) adverbial morphosyntax can be used with quantity superlatives on relative readings. We propose that the commonalities between quantity and adverbial superlatives are due to the fact that comparison is being made among degrees or events rather than individuals, and offer a compositional account.
\end{abstract}

Keywords: gradability, quantification, superlatives, typology, semantics

\section{Introduction}

Adnominal superlatives of ordinary gradable adjectives famously give rise to both absolute and relative readings, as illustrated in (1a) and (1b) respectively. But other classes of superlatives produce a different set of readings, shown in (2) through (4).

QUALITY SUPERLATIVES (ADNOMINAL)

a. Kim climbed the highest mountain in Arizona.

[absolute]

'... higher than all other mountains in Arizona'

b. Joan counted to the highest number.

[relative]

'Joan counted to a higher number than anyone else'

QUANTITY SUPERLATIVES (ADNOMINAL)

a. Kim likes most cats.

'...the majority of cats'

[proportional]

* Many thanks to Dylan Bumford, Irene Heim, Martin Hackl, and Stephanie Solt for their generous feedback on this work at the SALT conference. We also thank the many consultants and linguists who kindly provided data and judgments, especially Stavroula Alexandropoulou, Nino Amiridze, Nora Aranberri, Athulya Aravind, Itamar Kastner, Hadas Kotek, Jon Ander Mendia, Liljana Mitkovska, Maria Savić, Mia Yeffet, and Mikko Yrjönsuuri. Golsa Nouri-Hosseini provided heroic assistance with data collection and analysis. Funding for this work came from the Swedish Research Council project Most and more: Quantity superlatives across languages (2015-01404), awarded to PI Elizabeth Coppock at the University of Gothenburg. 
b. We got the most snow on Friday.

[relative]

'We got more snow on Friday than on any other day'

QUALITY SUPERLATIVES (ADVERBIAL)

Pam ran the fastest.

[relative]

'Pam ran faster than anyone else'

QUANTITY SUPERLATIVES (ADVERBIAL)

Nancy liked it the least.

[relative]

'Nancy liked it less than everyone else'

Superlatives of quantity words such as many (henceforth quantity superlatives) appear not to have absolute readings, although they do have proportional readings in English as in (2a), as well as relative readings as in (2b) (Hackl 2000, 2009). However, looking broadly across languages, we find that a proportional reading for quantity superlatives is usually lacking (Coppock, Bogal-Allbritten \& NouriHosseini submitted; see also Pancheva 2015 and Dobrovie-Sorin \& Giurgea 2015). Adverbial superlatives, shown for quality and quantity respectively in (3) and (4), appear to have only relative readings as well (Coppock, Leffel, Scontras \& Kotek 2016). We refer to these generalizations as follows:

\section{(5) Markedness of proportional readings}

Quantity superlatives normally have only relative readings.

(6) Relative-only for adverbial superlatives

Adverbial superlatives have only relative readings.

We argue that the restricted range of readings for quantity and adverbial superlatives stems from an underlying similarity between them with respect to semantic type: the gradable predicate involved applies to entities that are not individuals, but rather degrees or events. In particular, quantity words like many or much denote predicates of degrees rather than individuals (contra Hackl 2000, 2009). Together with certain additional assumptions, this explains the typological asymmetry between quantity superlatives and quality superlatives, as well as structural affinities between quantity superlatives and adverbial superlatives. ${ }^{1}$

After illustrating the cross-linguistic picture in Sections 2 and 3, we present an account in Section 4 from which the markedness of proportional readings and the restriction of adverbial superlatives to relative readings can be derived. The account will also cast light on certain morphosyntactic patterns found across a wide range of languages:

1 This argument is developed more thoroughly in Coppock et al. (submitted). 
Forces at the interface of gradability and quantification

\section{Number-marking generalization}

Quantity superlatives never disagree in number with the associated noun on proportional readings, but on a relative reading, the superlative may show default agreement, disagreeing with the noun.

\section{Adverbial-relative connection}

When quantity superlatives disagree in number with the substance noun, they have the morphological shape of an adverbial superlative.

Both of these were observed for Germanic by Coppock (to appear); here we illustrate that they hold somewhat more broadly.

\section{When absolute readings are missing}

According to Hackl (2000, 2009), most is the superlative of many, and many is a gradable predicate of (possibly plural) individuals, mapping them to the number of atoms they contain. Hackl shows that a proportional reading of most can be seen as an absolute reading, given a certain assumption about the meaning of -est, under which it quantifies over non-overlapping rather than non-distinct individuals. From this perspective, the naive expectation is that proportional readings for most should be found in any language in which superlatives have absolute readings. But it is well-known that there are counterexamples to this naive prediction.

While cognates of most can have both relative and proportional readings, such readings are absent in e.g. Slavic languages (Pancheva \& Tomaszewicz 2012; Dobrovie-Sorin \& Giurgea 2015: i.a.) including Bulgarian (9).

(9) Maria pročete naj-mnogo(-to) statii.

Maria read SPRL-many(-DEF) article.PL

Relative: 'Maria read the most articles.'

(*Proportional: 'Maria read most of the articles.')

(Pancheva 2015: (16))

In general, proportional readings for quantity superlatives are highly typologically marked; Coppock et al. (submitted) estimate that the probability of a language having a proportional reading for the superlative of much or many is around $10 \%$.

Another class of superlatives that is typically - indeed, always - limited to relative readings is adverbial superlatives (Coppock et al. 2016). Sentence (10) only allows an interpretation in which Kim is contrasted with other climbers (i.e., on a relative reading). The sentence is nonsensical if Kim is the only climber (i.e., on an absolute reading).

(10) Kim climbed the highest. 
Relative: Kim climbed to a greater height than any other person did.

(*Absolute: Kim climbed to a greater height than any other height.)

(*Absolute: Kim participated in a climbing event higher than any other climbing event.)

The same pattern is also attested in French, German, Italian, and Hebrew. In each language, adnominal superlatives are ambiguous between absolute and relative readings while adverbial ones only allow relative readings. Thus quantity superlatives and adverbial superlatives are semantically similar, insofar as both typically have only relative readings.

\section{Agreement Generalizations}

\subsection{Number-marking generalization}

Investigation of a wide range of languages reveals the following generalization about number-marking in superlatives: Quantity superlatives never disagree in number with the associated noun on proportional readings, but on a relative reading, the superlative may show default agreement, disagreeing with the noun.

Some of the relevant observations were made for Scandinavian languages in Coppock to appear. In Faroese, proportional readings require the determiner to agree with the noun for number (and gender), as with plural determiner toer and plural substance noun smák $\phi k u r$ 'cookies':

$$
\begin{aligned}
& \ldots \text { og eg át tær flest-u (av teimum). } \\
& \ldots \text { and I ate DEF.FEM.PL many.SPRL-WK of them.DAT.PL } \\
& \text { "[Mom baked cookies yesterday] and I ate most of them.' }
\end{aligned}
$$

In (12), we instead find a neuter singular form quantity superlative (flest), regardless of the plurality of the substance noun. Sentences with such mismatches only allow a relative reading.

Eg eri tann í familjuni, sum etur flest køkur.

I am DEM in family.DAT.DEF as eats many.SPRL.NEU.SG cookie.PL ' $I$ ' $m$ the one in the family who eats the most cookies.'

(Faroese)

The same sort of pattern emerges in Swedish and other Mainland Scandinavian languages, where the proportional reading of a quantity superlative with a plural noun (e.g. kakor 'cookies') mandates the use of plural definite determiner de:

$$
\text { ... och jag åt de flest-a av dem. }
$$$$
\ldots \text { and I ate DEF.PL many.SPRL-WK of them }
$$ 
Forces at the interface of gradability and quantification

'[Mom baked cookies yesterday] and I ate most of them.' (Swedish)

Quantity superlatives with default agreement are unambiguously relative. Here we find the historically neuter singular form flest, despite the plurality of the noun instrument 'instruments'.

Av alla barn i skolan är jag den som spelar flest of all kids in school.DEF am I DEM as plays many.SPRL

instrument.

instrument.PL

'Of all the kids in my school, I'm the one who plays the most instruments.'

(Swedish)

German shows a slightly different pattern. Sentences of the shape in (15) are ambiguous between relative and proportional meanings (Hackl 2009). Here, the definite determiner and superlative word exhibit full agreement with the noun Kinder.

$$
\text { Die meisten Kinder an meiner Schule spielen gerne Musik. }
$$
DEF.PL many.SPRL.WK child.PL in my school play gladly music 'Most of the kids who go to my school like to play music.' (German)

Roelandt (2016b) observes, however, that some speakers also accept sentences like (16), where the neuter singular determiner (plus locative) am is mismatched with the noun Plätzchen 'cookies'. Superlatives with am only admit relative readings.

Ich bin das Mitglied unserer Familie, das am meisten I am the member our family that on_DEF.NEU.SG much.SPRL Plätzchen isst. cookie.PL eats 'I am the member of our family who eats the most cookies.'

(German)

Roelandt (2016a) shows for Flemish Dutch that proportional readings arise when the determiner agrees in number with the substance noun (e.g. bergen 'mountains'):

$$
\begin{aligned}
& \text { Jan heeft de meeste bergen beklommen. } \\
& \text { John has the.PL many.SPRL mountain.PL climbed } \\
& \text { 'John has climbed most (of the) mountains.' (Flemish, Roelandt 2016a) }
\end{aligned}
$$

In (18), the singular determiner het is used with the same plural noun bergen 'mountains'. Superlatives in which the determiner and substance noun are mismatched in number are unambiguously relative: 
We even find the same pattern in Basque. Etxeberria (2005) observes that the reading available for quantity superlatives with plural substance nouns correlates with the presence of the plural determiner $-a k$ on the superlative expression gehi-en. When the plural determiner $-a k$ is present, as below where it matches the plural substance noun liburu, the superlative only has a proportional reading.

Liburutegi horrek ditu liburu gehi-en-ak.

library that.ERG has book much-SPRL-DEF.PL

Proportional: 'That library has most of the books.'

(*Relative: 'That library has the most books.')

(Basque)

(Etxeberria 2005: 91)

If plural $-a k$ is omitted, the superlative only has a relative reading:

Liburutegi horrek ditu liburu gehi-en.

library that.ERG has book much-SPRL

Relative: 'That library has the most books.'

(*Proportional: 'That library has most of the books.')

(Basque)

(Etxeberria 2005: 91)

\subsection{Adverbial-relative connection}

Cases of disagreement between superlatives and substance nouns reveal a second generalization: When quantity superlatives disagree in number with the substance noun, they have the morphological shape of an adverbial superlative. Structural similarities of this type were first observed by Roelandt (2016b) for Germanic languages including Flemish Dutch and German. In Flemish Dutch, the 'mismatching' neuter singular determiner het seen in (18) is also found in adverbial superlatives:

\section{Mijn zus kan het hardst lopen. 1 POSS sister can DEF.NEU.SG fast.SPRL run 'My sister can run the fastest.'}

Likewise, the German 'mismatching' locative neuter singular determiner am seen in (16) also occurs in adverbial superlatives:

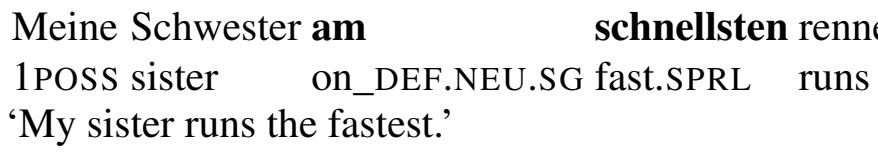

(German) 
Forces at the interface of gradability and quantification

Faroese and Swedish also fit this pattern. The default form taken by quantity superlative words in the unambiguously relative sentences (12) through (14) is also found in advebial superlatives:
a. Systir mín rennur skjótast.
sister 1POSS runs fast.SPRL
'My sister runs the fastest.'
b. Min syster springer fortast. 1 POSS sister runs fast.SPRL 'My sister runs the fastest.'

(Faroese)

(Swedish)

We find the same pattern in Basque. The determiner $-a k$ is obligatorily absent in adverbial superlatives, just as with quantity superlatives with relative readings (20):

$$
\begin{aligned}
& \text { Gurasoek sufritu dutu gehi-en. } \\
& \text { parent.PL.ERG suffer AUX much-SPRL } \\
& \text { 'The parents suffered the most.' }
\end{aligned}
$$

(Basque, Hualde \& de Urbina 2003: 2051)

While we have thus far focused on the adverbial-relative connection with respect to (the absence of) agreement, other languages may instantiate this connection in other ways. $^{2}$ In Spanish and Italian, the key is not number marking but rather the distribution of the definite determiner. Quality superlatives on any reading are expressed with comparative morphology and the definite determiner:

2 As a potential direction for future work, we note for Hebrew and Finnish that the same quantity words occur in both adverbial and adnominal quantity superlatives with relative readings. Unlike ordinary gradable adjectives found in quality superlatives, harbe and eniten fail to bear any indication of agreement for number (or gender or case) with the substance noun. This kind of example may be another way in which the agreement generalizations can manifest in particular languages.
a. ani dibar-ti im haxi harbe lakox-ot.
I speak-1sg with SPRL much customer-PL.MASC 'I spoke with the most customers.'
b. ani ohev-et ot-ax haxi harbe.
I love-1SG.FEM ACC-3SG.MASC SPRL much
'I love you the most.'

(Hebrew)

(ii) a. Turkkin mukauduttava eniten.

Turkey adapt much.SPRL

'Turkey needs to adjust the most.'

b. Mutta minä meidän perheestä kuitenkin syön eniten keksejä.

but I 1PL.POSS family however eat much.SPRL cookie.PL

'But I am also the member of our family who eats the most cookies.' (Finnish) 
Es difícil porque mi mamá hace las galletas más it.is difficult because 1POSS mother makes DEF.PL cookie.PL CMPR ricas del mundo. delicious.PL in_DEF world 'It is difficult because my mom makes the yummiest cookies in the world.'

However, the definite determiner is obligatorily absent both from quantity superlatives with relative readings (26a) and from adverbial superlatives (26b):

a. Yo soy el que toca más instrumentos.

I am the.one who plays CMPR instrument.PL 'I am the one who plays the most instruments.'

b. Juan es el que corre más rápido.

Juan is the.one who runs CMPR fast 'John is the one who runs the fastest.'

Parallel facts hold for Italian (Coppock \& Strand to appear).

Spanish (and Italian) quantity superlatives lack proportional readings; nouns like la mayoría 'the majority' are used instead. As such, we cannot say that there is an adverbial-relative connection to the exclusion of proportional readings. However, the observed differences with quality superlatives are consistent with a connection between adverbial superlatives and quantity superlatives with relative readings.

Greek presents an interesting case. Quantity adverbial superlatives bear definiteness marking while quality adverbial superlatives do not (27):

O Pavlos milaei pio grigora apo olus ke to perissótero. DEF Paul talks CMPR fast of all.ACC and DEF much.CMPR 'Paul talks the fastest of all and the most.'

(Greek)

Thus there is a split between quality and quantity in the adverbial domain in Greek. This suggests that adverbial quantity superlatives, like adnominal quantity superlatives, involve comparison between degrees, while adverbial quality superlatives involve comparison between events, in a sense that we will make more precise without further ado.

\section{Proposal}

\subsection{Schematic representations}

As an aide to explanation, we introduce a schema for describing the various meaning components in a superlative sentence. Consider first a relative reading of the 
Forces at the interface of gradability and quantification

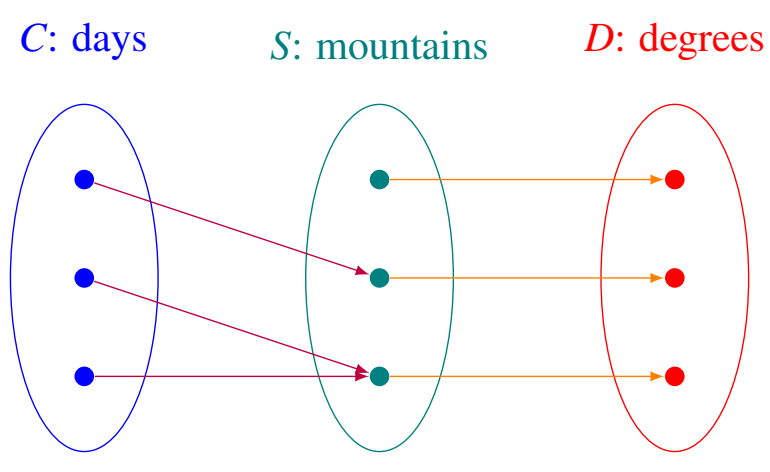

$R$ : John climbed $y$ on $x \quad G: y$ is $d$-high

Figure 1 Schematic analysis for John climbed the highest mountain on Tuesday .

following example.

John climbed the highest mountain on Tuesday $F$.

The components of this sentence's interpretation are depicted in Figure 1, where the parts of the sentence are color-coded to match the parts of the schema corresponding to their meanings.

Each of the three ovals in the schema represents a set: days (focal alternatives), mountains, and degrees. Days and mountains are sets of individuals, while degrees is a set of degrees. Members of set days are mapped onto members of set mountains by the relation John climbed y on $x$. Members of set mountains are mapped onto members of set degrees by the relation $y$ is $d$-high.

Following the terminology of Coppock \& Beaver (2014), the position occupied by the set days will be more generally referred to as the contrast set $(C)$. The contrast set is determined by the placement of focus marking. The position occupied by the set mountains will be referred to as the measurand set $(S)$ (cf. measured entities, target argument). Members of the contrast set $(C)$ are mapped onto members of the measurand set $(S)$ by the association relation $(R)$. Measurands (individuals) are mapped onto degrees by a measure relation $(G)$.

\subsection{Applying the schema}

The schema just introduced is sufficiently general to model a wide range of superlative uses. An absolute reading arises when the association relation $R$ is identity, so that the contrast set is identical to the measurand set $(C=S)$. Both are sets of individuals. The distinction between the contrast set and the measurand set collapses 


\begin{tabular}{lcccc}
\hline & $C$ & $S$ & $C=S ?$ & $G$ \\
Quality/absolute as in (1a) & $\langle e, t\rangle$ & $\langle e, t\rangle$ & yes & $\langle e, d\rangle$ \\
Quality/relative as in (1b) & $\langle e, t\rangle$ & $\langle e, t\rangle$ & no & $\langle e, d\rangle$ \\
Quantity/proportional as in (2a) & $\langle e, t\rangle$ & $\langle e, t\rangle$ & yes & $\langle e, d\rangle$ \\
Quantity/relative as in (2b) & $\langle e, t\rangle$ & $\langle d, t\rangle$ & no & $\langle d, d\rangle$ \\
Quality/adverbial as in (3) & $\langle e, t\rangle$ & $\langle v, t\rangle$ & no & $\langle v, d\rangle$ \\
Quantity/adverbial as in (4) & $\langle e, t\rangle$ & $\langle d, t\rangle$ & no & $\langle d, d\rangle$
\end{tabular}

Table 1 Classifications for some superlative constructions.

in this case, yielding a straightforward situation involving a single comparison class, hence an absolute reading of the sentence. To take a concrete example, an absolute reading for the sentence John climbed the highest mountain on Tuesday arises when the contrast set and measurand set consist of the same set of mountains. Each mountain is mapped onto its degree of height by the measure relation $G$ (height).

Table 1 summarizes how we take the schema to be instantiated in various cases. Each row corresponds to a distinct superlative construction. The first column gives the semantic type of the contrast set; the second column gives the type of the measurand set; the third column indicates whether or not the association relation is identity so that $C=S$; the final column gives the type of the measure relation.

In all of the cases represented in Table 1, the contrast set consists of individuals. There are examples with relative readings for which this appears not to be the case:

When did you have the most fun?

(contrast set of times)

(30) How big an apartment gives you the best value for your money? (contrast set of sizes)

However, we know of no cases of absolute readings where the contrast set is not made up of individuals. We assume, then, the following generalization:

\section{Constraint on association relations}

The only association relation of identity maps individuals to individuals.

When the association relation is not identity, the contrast set is associated with a licensor. There are several possible licensors, including focus, as in (28), wh(Szabolcsi 1986), and PRO (Heim 1999). If the measurand set consists of something other than individuals, then the contrast set must be identified by such a licensor.

In the case of adverbial quality superlatives, as in John ran the fastest, we 
Forces at the interface of gradability and quantification

assume that the contrast set consists of alternatives to John, while the measurands are events rather than individuals as they were for relative and absolute readings. The association relation can be paraphrased ' $x$ was an agent in running event $e$ ', and the measure relation can be paraphrased 'event $e$ has speed $d$ '. This result is derived from the assumption that an adverb like fast relates an event (type $v$ ) to a degree (type $d$ ).

For a relative reading of a quantity superlative (both adverbial and adnominal), we take the measurands to be degrees (or 'quantities'). This follows from the more basic assumption that quantity words measure the size of quantities, rather than the size of individuals (or pluralities thereof). This assumption has precedent in the proposals of Rett (2008) and Solt $(2009,2011)$, who treat quantity words as gradable properties of degrees or intervals, rather than individuals. These authors observe that quantity words such as many and much are unlike ordinary gradable adjectives in a number of respects, including serving as differentials (She is much taller than me; He has many more books than me, etc.).

\subsection{Accounting for the generalizations}

Under the schema above, adverbial and quantity superlatives with relative interpretations are unique among superlatives in that the measurands are not individuals but rather events or degrees. With this as our starting point, we can explain the two morphosyntactic generalizations if we also assume that agreement patterns reflect the semantic type of the measurand. Coppock (to appear) offers the Target-Domain Hypothesis, according to which the grammatical features exhibited by a superlative reflect the domain from which the target argument is drawn. This hypothesis can explain the data on the assumption that the target argument for the superlative is a measurand. This is the case for in situ analyses of superlatives. Under a movement analysis, however, the target argument for the superlative is arguably the licensor in the case of a relative reading. A more theory-neutral way of stating the additional assumption needed is as follows.

\section{Measurand-Domain Hypothesis}

The agreement features of a superlative are determined by the domain from which the measurands are drawn: If the measurands are drawn from a domain other than the set of individuals, then default agreement is expected in the absence of overriding factors.

Given only this, we would expect ordinary number agreement only if the target argument/measurand is an individual. But other factors appear to favor agreement between quantity words and the relevant nouns. Indeed, Schwarzschild (2006), building on Giusti (1997), argues on the basis of agreement between molti 'many.PL.MASC' 
and ragazzi 'boys' in Italian that quantity words should project a phrase that occupies a specifier position of Schwarzschild's MonP. In this specifier position, quantity words would be expected to show agreement with the Mon head, and hence the noun, as Mon is a functional projection that inherits its agreement features from the dominated nominal projection. Thus syntactic factors can conflict with the semantic agreement principle proposed here, yielding full agreement with quantity superlatives on relative readings. No such effect is visible in Italian because quantity superlatives do not involve any overt quantity word, but Romanian and Greek are cases that exhibit this phenomenon. In both of these languages, adnominal quantity superlatives show number agreement with the noun on both relative and proportional readings. This is shown for Greek in (33).

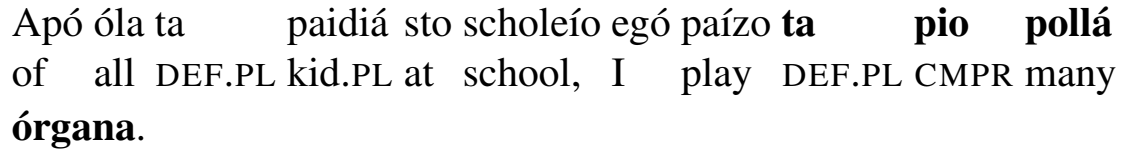

'Of all the kids in my school, I'm the one who plays the most instruments.' (Greek)

This account allows us to derive the number-marking generalization: On a proportional reading, quantity superlatives never disagree in number with the modified noun, whereas the superlative may show default agreement on a relative reading. If we assume that the measurands are individuals in the case of proportional readings, we correctly predict number agreement on adnominal quantity superlatives with proportional readings. We also correctly predict default agreement on quantity superlatives with relative readings because the measurands are degrees, not individuals.

Our assumptions also account for the adverbial-relative connection. Both adverbial superlatives and quantity superlatives with relative readings involve measurands of a non-individual type (events, degrees). All other superlatives use individual-type measurands. According to the measurand-domain hypothesis, we expect agreement patterns to track the type of the measurand; mismatches arise only with non-individual types.

We can also derive the fact that adverbial superlatives only have relative readings. We have assumed that absolute readings only involve individuals because the only identity relation is one that maps individuals to individuals. With adverbial superlatives, the association relation cannot be one of identity because the measurands are events or degrees. Therefore, some licensor is needed in order to determine a non-trivial association relation; hence relative readings.

Finally, we can explain the markedness of proportional readings. As outlined 
above, we assume that the basic function of a quantity word is to measure the size of quantities, rather than the size of individuals. Given this assumption, the measurand set of a quantity superlative will by default contain degrees rather than individuals. Since the measurand set is distinct from the contrast set, an appropriate licensor - such as focus — is needed to determine the association relation that maps the contrast set onto the measurand set. Our account thus correctly predicts relative readings to arise by default for quantity superlatives.

A proportional reading, on the other hand, requires more work to obtain. In particular, quantity words must undergo a change in meaning. Above, we claimed that the measurands in a proportional reading are plural individuals rather than degrees. We suggest that a change takes place in the meaning of many such that the contribution of a silent Meas head (cf. Schwarzschild's (2006) Mon, i.a.) is attributed to many. After this change in the meaning of many has taken place, both the contrast set and the measurands are individuals, so the association relation between them is one of identity. As such, proportional readings do not require, or display, any kind of focus sensitivity. This explains not only the agreement facts discussed above, but also correctly captures the meaning of the proportional reading.

What we end up with is similar to Hackl's (2009) treatment of proportional readings, insofar as the superlative of many denotes the most numerous plurality of a salient bunch. ${ }^{3}$ It is even more similar to the account of Hoeksema (1983), according to which de meeste in Dutch picks out the greatest plurality in a contextually given set of pluralities.

Our explanation for the limited distribution of proportional readings is in the spirit of Pancheva (2015), who linked relative and proportional readings to distinct kinds of pseudopartitive structures, namely individuating and measure. The distinction can be illustrated with the following contrast:

a. John broke two glasses of water.

b. John added two glasses of water to the soup.

[individuating]

[measure]

In individuating pseudopartitives (34a), the container or measure noun (glass) is the head, whereas in measure pseudopartitives (34b), the substance noun (water) is the head (Doetjes 1997; Landman 2004; Rothstein 2009; Alexiadou, Haegeman \& Stavrou 2007).

According to Pancheva, pseudopartitive structures that underlie quantity superlatives contain an abstract noun NUMBER instead of a measure noun like glass. Proportional readings arise when the pseudopartitive has a measure structure. Relative

3 We further note that our schema also reflects Hackl's insight that proportional readings are in some sense related to absolute readings. While the two readings do not arise through precisely parallel steps in our account, they are the only superlative readings with an identity association relation. 
readings of quantity superlatives arise from pseudopartitives with an individuating structure, such that the superlative (LARGEST) modifies NUMBER. In her account, languages differ with respect to which of these structures they permit, with restrictions on the distribution of measure pseudopartitives determining the distribution of proportional readings.

Pancheva's account of relative readings is therefore in line with the tendency for singular (or default) agreement in quantity superlatives with relative readings: the target argument (or measurand) would be a degree corresponding to the abstract noun NUMBER. This leads naturally to the prediction that there would be singular agreement on the superlative in the case of a relative reading, and plural agreement in the case of a proportional reading (although it does not explain why default gender features would be expected to appear).

Pancheva's account faces certain challenges. As Wilson (2016: 17) points out, it predicts that He ate the largest (of) cookies can mean He ate the largest number of cookies. And as discussed by Coppock et al. (submitted), it does not explain why de occurs with quantity superlatives in Mandarin. A core insight to be preserved from Pancheva's (2015) account, though, is that relative readings of quantity superlatives involve measurement of degrees rather than individuals. We give an explicit account of how this works in the following section.

\subsection{Derivations}

The schema illustrated above in Figure 1 is intended to be a theory-neutral way of describing any given reading of a superlative. ${ }^{4}$ However, it rather directly reflects the analysis of Coppock \& Beaver (2014), which is quite similar in spirit to that of Farkas \& É. Kiss (2000). Here as well, we implement an analysis of the superlative morpheme that draws directly on the notions depicted in the schema presented above. Our lexical entry for -est invokes free parameters for the association relation (R) and the contrast set $(\mathrm{C})$; this is why they are written in bold:

$$
\begin{aligned}
& \text {-est } \rightsquigarrow \lambda G_{\langle\tau,\langle d, t\rangle} \lambda y_{\tau} . \partial(\mathbf{C}(\mathbf{x}) \wedge \mathbf{R}(\mathbf{x}, y)) \wedge \sup (\mathbf{x}, \mathbf{R} \circ G, \mathbf{C}) \\
& \text { where: } \\
& \quad \cdot \sup (x, G, C) \text { means } x \text { is more } G \text { than any distinct } x^{\prime} \text { in } C \\
& \quad \cdot \tau \text { : } e \text { (individual), } d \text { (degree) or } v \text { (event) } \\
& \quad \cdot R \text { relates individuals in } C \text { to things of type } \tau
\end{aligned}
$$

4 The general schema should be applicable regardless of the semantic roles (if any) played by movement of -est and the definite determiner. For discussion of other theories of superlative meaning, see e.g. Heim 1999; Sharvit \& Stateva 2002; Pancheva \& Tomaszewicz 2012; Szabolcsi 2012; Bumford 2017; and works cited therein. 
Forces at the interface of gradability and quantification

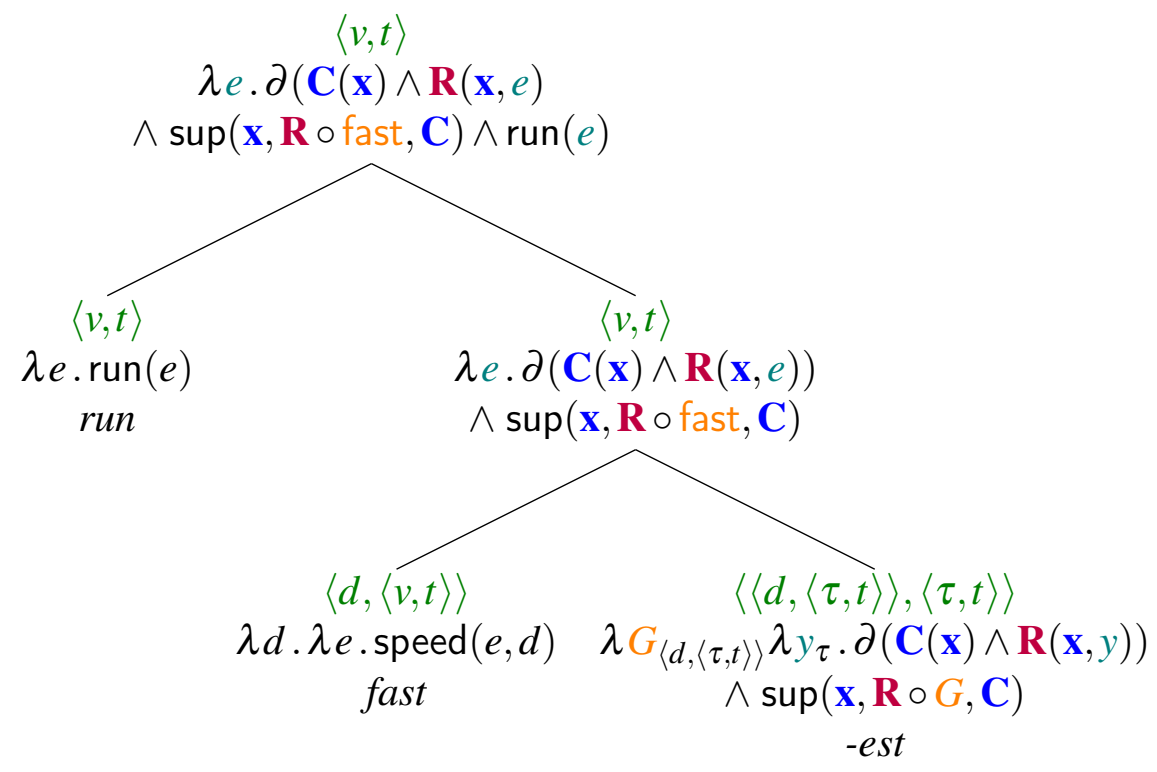

Figure 2 Derivation for run fastest

- $R \circ G$ denotes the relational composition of $R$ and $G$, a relation between an object $x$ and a degree $d$ that holds if there is a $y$ such that $R(x, y)$ and $G(y, d)$

The hypothesis that the agreement features reflect the semantic type of the measurands can now be expressed formally as a principle that the superlative exhibits default agreement when $\tau \neq e$.

We adopt a standard analysis of a gradable adjective like high, as in (36). For adverbs like fast, we assume that they are gradable predicates of events, as in (37). We analyze quantity words as in (38), where the use of the salient extensive measure function $\mu$ is inspired by Wellwood (2014).

$$
\begin{array}{ll}
\text { high } \rightsquigarrow \lambda d . \lambda x . \text { height }(x)=d & \langle d, e t\rangle \\
\text { fast } \rightsquigarrow \lambda d . \lambda e \cdot \operatorname{speed}(e)=d & \langle d, v t\rangle \\
\text { mисh } \rightsquigarrow \lambda d \cdot \lambda d^{\prime} \cdot \mu\left(d^{\prime}\right)=d & \langle d, d t\rangle
\end{array}
$$

where $\mu$ is a salient extensive measure function

An extensive measure function of a degree is just an identity function. But the treatment in (38) brings out the parallel between quantity words and other gradable predicates.

The derivation in Figure 2 illustrates the analysis of an adverbial superlative. 
(Note that fast is used as an abbreviation for the translation of fast.) The key thing to notice about this case is that $\tau$ is of type $v$, hence relative readings and default agreement. The members of $\mathbf{C}$ will have to be established via an appropriate licensor, hence focus-sensitivity.

Let us now consider quantity superlatives. A degree phrase headed by a quantity word will end up denoting a property of degrees, so some sort of compositional glue is needed in order to connect this property to the meaning of the noun, when a nominal complement is taken. To compose a quantity expression with a noun, we adopt the assumption that there is a silent measure head; see for example Schwarzschild 2002, 2006; Kayne 2005, Nakanishi 2007a,b; Rett 2014; Solt 2009, 2015; and references cited therein. Here, we assume the attributive form of Rett's (2014) individual M-Op (Rett's (57a)). ${ }^{5}$

$$
\begin{aligned}
& \text { M-Op } \rightsquigarrow \lambda P \lambda d \lambda x . P(x) \wedge \mu(x)=d \\
& \text { where } \mu \text { is a salient extensive measure function }
\end{aligned}
$$

The derivation in Figure 3 then yields a relative reading for an adnominal quantity superlative such as (the) most books.

Note: many is used as an abbreviation for the translation of many here. The upward-pointing arrow subscripted with IOTA indicates the IOTA type-shifting operation, converting a predicate to an individual. In the case that the definite article appears in the string, the article would either take the place of the IOTA shift, if a Fregean analysis is adopted, or the IOTA shift would apply to the combination of the article with the predicate, if an analysis along the lines of Coppock \& Beaver (2015) is adopted.

We propose that what enables proportional readings to arise is a reanalysis such that the contribution of $\mathrm{M}-\mathrm{Op}$ is attributed to many. This yields the analysis in Figure 4. Now because the predicate to which - est attaches is a gradable predicate of individuals, an absolute reading can obtain, where the contrast set and the measured entities are identified. If we assume furthermore that the contrast set contains only two pluralities corresponding to a partition over the set picked out by the head noun, then we get a 'more than half' interpretation. (This would be in the spirit of Hoeksema's (1983) analysis of proportional readings of quantity superlatives in Dutch.) In order for this analysis to become available, many must undergo a reanalysis. If our proposal is on the right track, then the markedness of proportional readings suggests that such a reanalysis is not a common one.

One might imagine an alternative hypothesis within the present framework of assumptions whereby many simply expands the range of subjects it can apply to,

5 The entry for M-Op adopted here also has the entry of Nakanishi's (2007b) $\mu$ operator, but with the property and degree arguments taken in opposite order. 
Forces at the interface of gradability and quantification

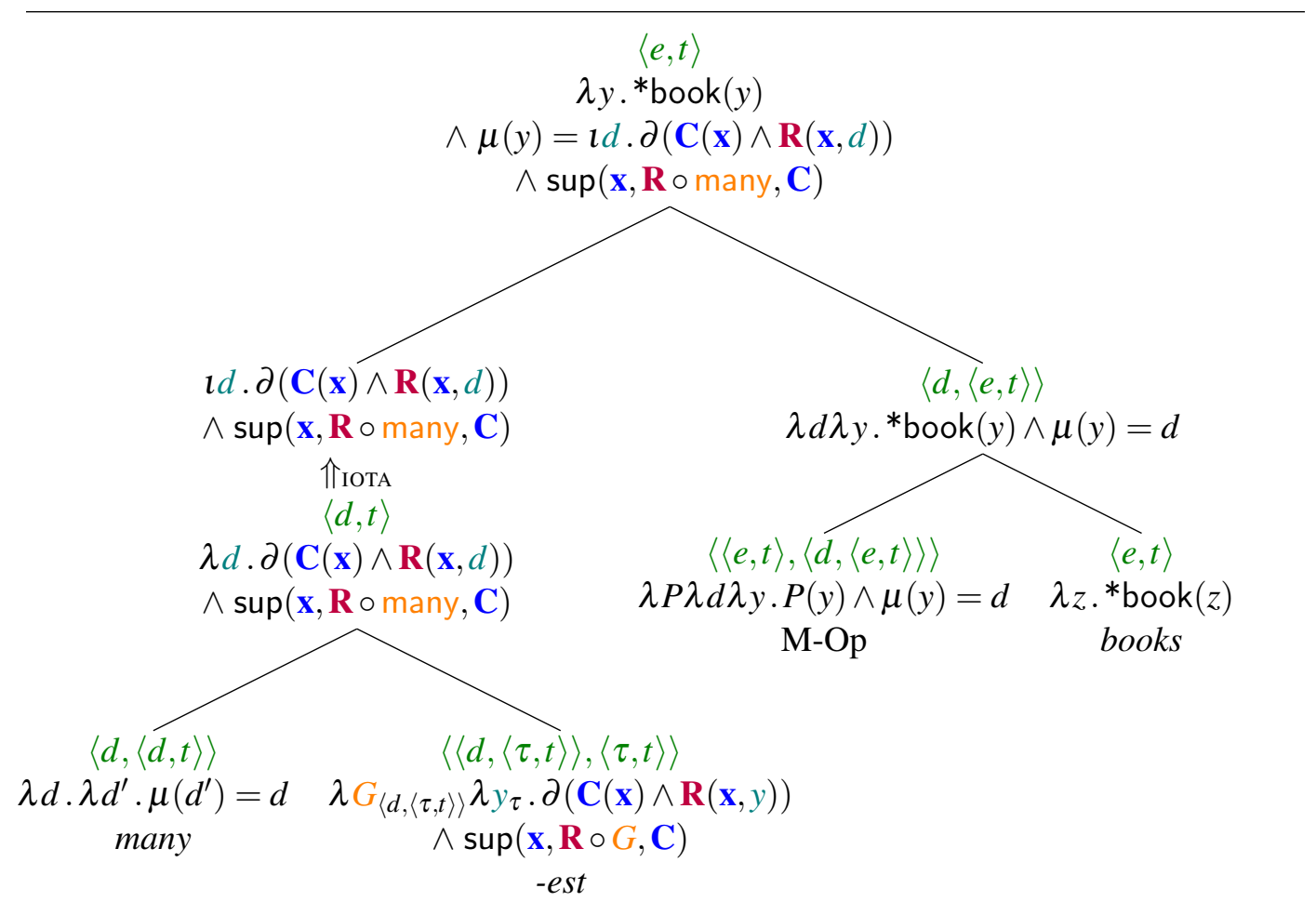

Figure 3 Derivation for (the) most books on a relative reading.

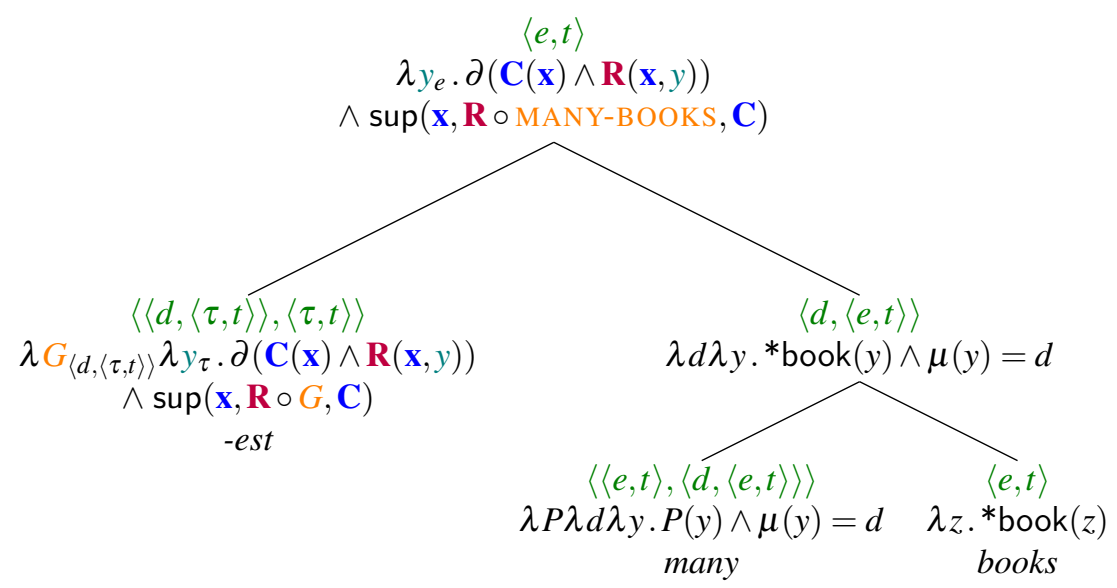

Figure 4 Derivation for most books on a proportional reading. 
from degrees only, to individuals as well. But this would seem to falsely predict that quantity words are more apt to appear predicatively in languages with proportional readings. Although there are predicative uses of many and few in English, these are limited, as Solt (2009) discusses. The reanalysis hypothesized here would only produce individual-measurand readings for quantity words in attributive position. The proposal does have broader consequences for attributive many and more in languages with proportional readings, which should be tested in future work.

\section{Summary}

Despite significant cross-linguistic variability in the morphosyntax of quantity superlatives, we nevertheless find certain generalizations at this border between gradability and quantification, namely: (i) proportional readings for quantity superlatives are typologically marked; (ii) adverbial superlatives have only relative readings; (iii) quantity superlatives agree in number with the noun on proportional, but not relative readings; (iv) adverbial morphosyntax can be used with quantity superlatives on relative readings.

We have proposed an account of quantity words and superlative meaning that allows us to capture these generalizations, summarized in (40).
a. In the case of an absolute reading, the contrast set is identical to the measurand set.
b. If the contrast set is not identical to the measurand set, its identity is
signalled by an appropriate licensor for a relative reading (e.g. focus).
c. The only association relation of identity maps individuals (type $e$ ) to individuals.
d. With quantity superlatives, the measurands are degrees (type $d$ ).
e. With adverbial superlatives, the measurands are events (type $v$ ).

Together, these assumptions correctly derive the markedness of proportional readings, and the fact that adverbial superlatives have only relative readings: Since both characterize non-individuals, the association relation cannot be identity, so the contrast set must be distinct from the measurands and identified by a licensor for relative readings. These assumptions also shed light on the number-marking generalization and the adverbial-relative connection: Both quantity and adverbial superlatives have the morphosyntax of predicates that do not apply to individuals. But when the contribution of M-Op is attributed to many, the measurands become individuals; hence number agreement on proportional readings. This kind of analysis is rare, and limited to contexts where the superlative is an attributive modifier of the noun. In future work, the consequences of this analysis for the interpretation of attributive many and more should be investigated. 
Forces at the interface of gradability and quantification

\section{References}

Alexiadou, Artemis, Liliane Haegeman \& Melita Stavrou. 2007. Noun Phrase in the Generative Perspective, vol. 71 Studies in Generative Grammar. Berlin: Mouton de Gruyter.

Bumford, Dylan. 2017. Split-scope definites: Relative superlatives and Haddock descriptions. Linguistics and Philosophy 40(6). 549-593. https://doi.org/10. 1007/s10988-017-9210-2.

Coppock, Elizabeth. to appear. Quantity superlatives in Germanic, or, life on the fault line between adjective and determiner. Journal of Germanic Linguistics (to appear).

Coppock, Elizabeth \& David Beaver. 2014. A superlative argument for a minimal theory of definiteness. In Todd Snider (ed.), Semantics and Linguistic Theory (SALT) 24, 177-196. Ithaca, NY: CLC Publications. http://dx.doi.org/10.3765/ salt.v24i0.2432.

Coppock, Elizabeth \& David Beaver. 2015. Definiteness and determinacy. Linguistics and Philosophy 38(5). 377-435.

Coppock, Elizabeth, Elizabeth Bogal-Allbritten \& Golsa Nouri-Hosseini. submitted. Universals in superlative semantics. Manuscript, Boston University and University of Gothenburg.

Coppock, Elizabeth, Tim Leffel, Gregory Scontras \& Hadas Kotek. 2016. Adverbial superlatives. Presentation at the Some Institutes for Advanced Study Summer Institute meeting, July 2016.

Coppock, Elizabeth \& Linnea Strand. to appear. Most vs. the most in languages where the more means most. In Ana Aguilar-Guevera, Julia Pozas Loyo \& Violeta Vázquez Rojas Maldonado (eds.), Definiteness Across Languages, Language Science Press.

Dobrovie-Sorin, Carmen \& Ion Giurgea. 2015. Quantity superlatives vs. proportional quantifiers: A comparative perspective. 25th Colloquium on Generative Grammar, Bayonne.

Doetjes, Jenny Sandra. 1997. Quantifiers and Selection. Leiden, Netherlands: Leiden University $\mathrm{PhD}$ dissertation.

Etxeberria, Urtzi. 2005. Quantification and domain restriction in Basque. Lejona, Spain: University of the Basque Country (UPV/EHU) PhD dissertation.

Farkas, Donka \& Katalin É. Kiss. 2000. On the comparative and absolute readings of superlatives. Natural Language and Linguistic Theory 18. 417-455. https: //doi.org/10.1023/A:1006431429816.

Giusti, Giuliana. 1997. The categorial status of determiners. In Lilliane Haegeman (ed.), The New Comparative Syntax Longman Linguistics Library, 95-124. Longman. 
Hackl, Martin. 2000. Comparative quantifiers. Cambridge, MA: MIT PhD dissertation.

Hackl, Martin. 2009. On the grammar and processing of proportional quantifiers: most vs. more than half. Natural Language Semantics 17. 63-98. https://doi. org/10.1007/s11050-008-9039-x.

Heim, Irene. 1999. Notes on superlatives. Manuscript, MIT.

Hoeksema, Jack. 1983. Superlatieven. TABU 13(101-106).

Hualde, José Ignacio \& Jon Ortiz de Urbina. 2003. A Grammar of Basque, vol. 26 Mouton Grammar Library. De Gruyter Mouton.

Kayne, Richard S. 2005. Some notes on comparative syntax, with special reference to English and French. In Oxford Handbook of Comparative Syntax, Oxford University Press. https://doi.org/10.1093/oxfordhb/9780195136517.001.0001.

Landman, Fred. 2004. Indefinites and the Type of Sets. Malden, MA: Blackwell. https://doi.org/10.1002/9780470759318.

Nakanishi, Kimiko. 2007a. Formal Properties of Measurement Constructions. Berlin: Mouton de Gruyter.

Nakanishi, Kimiko. 2007b. Measurement in the nominal and verbal domains. Linguistics and Philosophy 30. 235-276.

Pancheva, Roumyana. 2015. Quantity superlatives: The view from Slavic and its cross-linguistic implications. In Chicago Linguistic Society (CLS) 49, Chicago, IL: The Chicago Linguistic Society.

Pancheva, Roumyana \& Barbara Tomaszewicz. 2012. Cross-linguistic differences in superlative movement out of nominal phrases. In Nathan Arnett \& Ryan Bennett (eds.), 30th West Coast Conference on Formal Linguistics (WCCFL), 292-302. Somerville, MA: Cascadilla Press.

Rett, Jessica. 2008. Degree modification in natural language. New Brunswick, NJ: Rutgers University $\mathrm{PhD}$ dissertation.

Rett, Jessica. 2014. The polysemy of measurement. Lingua 143. 242-266. https: //doi.org/10.1016/j.lingua.2014.02.001.

Roelandt, Koen. 2016a. Most or the art of compositionality. Leuven, Belgium: University of Leuven PhD dissertation.

Roelandt, Koen. 2016b. Relative most compared. KrowFest 2016.

Rothstein, Susan. 2009. Individuating and measure readings of classifier constructions: evidence from Modern Hebrew. Brill's Annual of Afroasiatic Languages and Linguistics 1. 106-145.

Schwarzschild, Roger. 2002. The grammar of measurement. In B. Jackson (ed.), Semantics and Linguistic Theory (SALT) 12, 225-245. Ithaca, NY: Cornell University. http://dx.doi.org/10.3765/salt.v12i0.2870.

Schwarzschild, Roger. 2006. The role of dimensions in the syntax of noun phrases. Syntax 9(1). 67-110. https://doi.org/10.1111/j.1467-9612.2006.00083.x. 
Forces at the interface of gradability and quantification

Sharvit, Yael \& Penka Stateva. 2002. Superlative expressions, context, and focus. Linguistics and Philosophy 25. 453-505. https://doi-org.ezproxy.ub.gu.se/10. 1023/A:1020875809794.

Solt, Stephanie. 2009. The Semantics of Adjectives of Quantity. New York, NY: The City University of New York $\mathrm{PhD}$ dissertation.

Solt, Stephanie. 2011. How many most's? In Ingo Reich, Eva Horsch \& Dennis Pauly (eds.), Sinn und Bedeutung 15, 565-580. Saarland University Press.

Solt, Stephanie. 2015. Q-adjectives and the semantics of quantity. Journal of Semantics 32. 221-273. https://doi.org/10.1093/jos/fft018.

Szabolcsi, Anna. 1986. Comparative superlatives. In Naoki Fukui, Tova Rapoport \& Elizabeth Sagey (eds.), Papers in Theoretical Linguistics, 245-265. Cambridge, MA: MITWPL.

Szabolcsi, Anna. 2012. Compositionality without word boundaries: (The) more and (the) most. In Anca Chereches, Neil Ashton \& David Lutz (eds.), Semantics and Linguistic Theory (SALT) 22, 1-25. Ithaca, NY: CLC Publications. http: //dx.doi.org/10.3765/salt.v22i0.2629.

Wellwood, Alexis. 2014. Measuring Predicates. College Park, MD: University of Maryland $\mathrm{PhD}$ dissertation.

Wilson, E. Cameron. 2016. Deriving the most internal reading. In Nadine Bade, Polina Berezovskaya \& Anthea Schöller (eds.), Sinn und Bedeutung 20, 779-797.

Elizabeth Coppock

621 Commonwealth Avenue

Boston, MA 02215

ecoppock@bu.edu
Elizabeth Bogal-Allbritten

Olof Wijksgatan 6

41255 Göteborg, Sweden

elizabeth.bogal-allbritten@gu.se 